\title{
Tunica vaginalis flap following 'Tubularised Incised Plate' urethroplasty to prevent urethrocutaneous fistulaa
}

\author{
Raashid Hamid, Aejaz A. Baba, Altaf Shera, Sarfaraz Ahmad \\ Department of Paediatric Surgery, SKIMS, Srinagar, Jammu and Kashmir, India
}

Address for correspondence: Dr. Raashid Hamid, Married Doctors Hostel, A-Block, Room No. S2, SKIMS Soura, Srinagar - 190011 , Jammu and Kashmir, India. E-mail: drraashidhamid@gmail.com

\section{ABSTRACT}

Introduction: Surgery for hypospadias has been continuously evolving, implying thereby that no single technique is perfect and suitable for all types of hypospadias. Snodgrass technique is presently the most common surgical procedure performed for hypospadias. Materials and Methods: We analysed the results of tunica vaginalis flap (TVF) as an additional cover to the tubularised incised plate (TIP) repair. Results: A total of 35 patients of hypospadias were repaired using TIP urethroplasty and TVF as a second layer. Mean age at the time of presentation was $6.63 \pm 3.4$ years. Post-operative complications namely wound infection, flap necrosis, scrotal haematoma, scrotal abscess, urethral fistula, meatal stenosis were recorded and analysed during follow-up period. Need for re-do surgery was considered as failure of the operative procedure. Out of 35 patients, $8(22.85 \%)$ patients had proximal penile hypospadias and $27(77.14 \%)$ patients had distal penile hypospadias. Mean post-operative follow-up was 24.53 months. During the follow-up complications noticed included wound infection $(n=2)$, urethrocutaneous fistula $(n=1)$ and meatal stenosis $(n=1)$. Wound infection was managed with appropriate antibiotics as per hospital policy/ culture and sensitivity reports. Meatal stenosis responded to bougie dilatation/calibration during follow-up. Conclusion: To conclude, TVF as an additional cover is associated with an acceptable complication rate and good cosmetic results if performed with meticulous tissue handling.

\section{KEY WORDS}

Hypospadias; tunica vaginalis flap; urethrocutaneous fistula

\section{INTRODUCTION}

nodgrass described the tubularised incised plate (TIP) urethroplasty technique in 1994. ${ }^{[1]}$ Many vascularised flaps such as dartos flap and tunica vaginalis flap (TVF) were introduced to overcome

\begin{tabular}{|l|l|}
\hline \multicolumn{2}{|c|}{ Access this article online } \\
\hline Quick Response Code: & Website: \\
\hline & www.ijps.org \\
\cline { 2 - 2 } & Dol: \\
\hline
\end{tabular}

the concerns of vascularity of the repaired site. ${ }^{[2]}$ Complications in the form of meatal stenosis, urethral stricture, urethrocutaneous fistula (UCF) and urethral

\begin{abstract}
This is an open access article distributed under the terms of the Creative Commons Attribution-NonCommercial-ShareAlike 3.0 License, which allows others to remix, tweak, and build upon the work non-commercially, as long as the author is credited and the new creations are licensed under the identical terms.
\end{abstract}

For reprints contact: reprints@medknow.com

How to cite this article: Hamid R, Baba AA, Shera A, Ahmad S.
Tunica vaginalis flap following 'Tubularised Incised Plate'
urethroplasty to prevent urethrocutaneous fistulaa. Indian J Plast
Surg 2015;48:187-91. 
diverticulum continue to occur in spite of the several advancements in urethroplasty techniques. Use of TVF has been suggested as an additional vascularised cover in TIP urethroplasty and is effective in reducing the UCF rates. ${ }^{[3]}$ The purpose of our study was to evaluate the outcome of TVF as an additional cover to TIP urethroplasty, particularly in relation to the occurrence of UCF and other complications.

\section{MATERIALS AND METHODS}

Our study was a prospective study from 2008 to 2013 and was a single surgeon experience. Patients having distal or proximal penile hypospadias (excluding scrotal and perineal hypospadias) were included in the study. Patients with a history of herniotomy, orchidopexy or orchidectomy were excluded in view of difficulty in harvesting the flap due to the previous surgery. Thirty-five patients were selected with the help of simple random sampling method, among those fulfilling the inclusion criteria. Age, location of urethral meatus, occurrence of fistula in previously operated cases and past history of surgery were noted. Patients were operated under general anaesthesia and caudal block was given to reduce post-operative pain. TVF was harvested from either side of the scrotum and applied as an additional cover during the standard TIP urethroplasty. A nasogastric tube of 6 or $8 \mathrm{Fr}$ size was used for an average of 8-10 days to drain the urine and to stent the urethroplasty repair. Patients were followed at regular intervals. Development of UCF was considered as operative failure.

\section{Surgical technique}

Ectopic urethral meatus was calibrated with 6 or $8 \mathrm{Fr}$ feeding tube after applying a stay suture at the glans. A

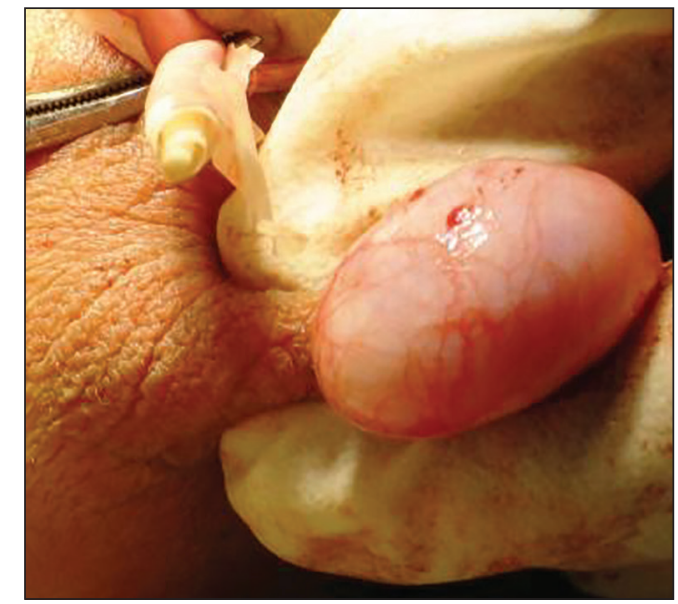

Figure 1: Testis delivered along with its coverings through scrotum sub-coronal circumferential incision was made extending ventrally in a ' $U$ ' shaped fashion around the ectopic meatus after applying a tourniquet. This was followed by degloving of the penis which corrected the accompanying chordee in 5 of the cases. In remaining 5 cases with chordee, dorsal plication was needed as an additional procedure for correcting the residual chordee. A midline shallow incision from ectopic meatus to the proposed new meatus was made on the urethral plate. The neourethra was constructed with 6-0 polyglactin sutures over the indwelling catheter. The urethroplasty was fashioned using interrupted sutures with knots outside the lumen. Lateral edges of corpus spongiosum, when available, were approximated to cover the neourethra. The hemiscrotum was explored by retracting the degloved skin at the root of penis or making a separate incision on the scrotum. After layer by layer dissection of the scrotum, the tunica vaginalis was exposed and testis was delivered into the wound [Figure 1]. A rectangular flap of tunica vaginalis was harvested with a vascular pedicle of adequate length so as to reach the site of insertion, that is, the neourethral tube through a tunnel beneath the penile skin [Figure 2]. The flap was spread over the neourethral tube and fixed with 6-0 polyglactin [Figure 3]. Glanuloplasty and meatal reconstruction was completed after adequate mobilisation of glanular flaps and achieving complete haemostasis using a low voltage bipolar diathermy [Figure 4]. Skin cover was completed with 6-0 polyglactin interrupted sutures. Surgical wound of scrotum was closed with 5-0 chromic catgut interrupted sutures.

In 5 patients who had developed UCF following previous surgery, urethra was catheterised with 6 or 8 Fr nasogastric tube, the UCF tract was excised and

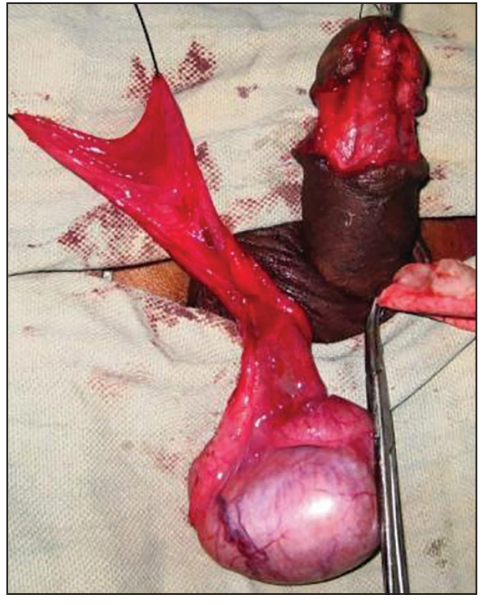

Figure 2: Tunica vaginalis flap raised from testis 


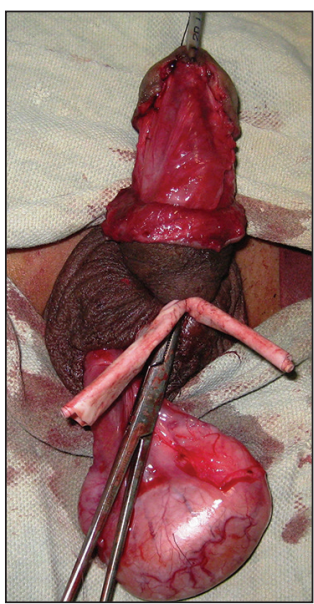

Figure 3: Tunica vaginalis flap being applied on neourethra

the urethra was closed primarily in two layers with 5-0 polyglactin suture. A small incision of about $2 \mathrm{~cm}$ was made at the penoscrotal junction and an adequate length TVF, devoid of cremasteric muscle fibres was harvested. Then this flap was tunnelled underneath the penile skin to the UCF site. TVF was fixed at the fistula site using 6-0 polyglactin suture.

Urethral catheter used as a urethral stent was connected to a urine collection bag for drainage of urine.

\section{RESULTS}

Among the 35 patients who underwent TIP urethroplasty with TVF, 5 patients had a second attempt at urethroplasty after they had developed UCF following previous surgery performed elsewhere. Age ranged from 2 to 12 years with a mean of $6.63 \pm 3.4$ years. Distal penile hypospadias was present in $27(77.14 \%)$ patients, and 8 $(22.85 \%)$ patients had proximal penile hypospadias. In our series of 35 cases, 10 patients had mild to moderate degree of chordee. Out of 35 patients, 16 (45.71\%) were circumcised including the five with UCF following surgical repair performed elsewhere, and the remaining 19 (34.28\%) were uncircumcised. Usually, the circumcision in our community is done for religious reasons at varying ages and in the 19 children who were uncircumcised, circumcision was done at the time of urethroplasty.

Postoperatively, 2 patients $(5.71 \%)$ developed wound infection which was managed with antibiotics as per hospital antibiotic policy or culture sensitivity report. UCF developed in 1 patient (2.85\%) [Table 1]. Meatal stenosis occurred in 1 patient (2.85\%) which was managed adequately with urethral dilatation/calibration. One

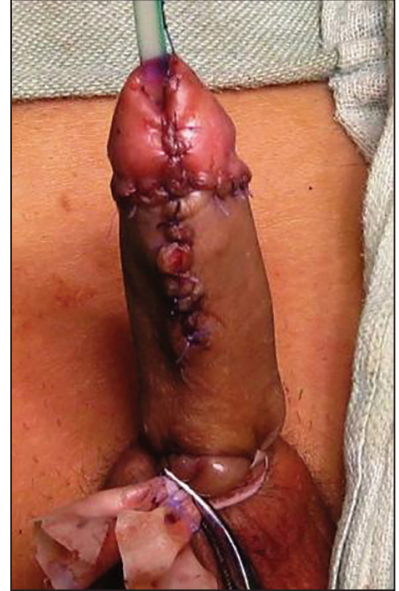

Figure 4: Skin cover and glanuloplasty completed

Table 1: Complications

\begin{tabular}{lcc}
\hline Complication & Number of patients & Percentage \\
\hline Wound infection & 2 & 5.71 \\
Scrotal haematoma & 1 & 2.85 \\
Meatal stenosis & 1 & 2.85 \\
Urethrocutaneous fistula & 1 & 2.85 \\
Post-operative chordee & 1 & 2.85 \\
\hline
\end{tabular}

patient had a scrotal abscess which was drained under local anaesthesia. In the present series, despite a long suture line in patients with proximal hypospadias, no fistula was seen among them, as harvesting a TVF is easy in proximal cases because the ectopic meatus lies closer to the scrotum.

The correlation of age, site of the meatus, presence or absence of chordee and preputial skin with the occurrence of UCF as independent factors did not have any statistical significance. The observations were in terms of age $(P=0.50)$, site of meatus $(P=1.00)$, presence of chordee $(P=1.00)$ and presence of prepuce $(P=1.00)$. Correlation between re-do surgery and fistula formation was also statistically insignificant $(P=1.00)$.

\section{DISCUSSION}

The use of interposition flaps in urethroplasty is welldocumented in literature. Triangular soft tissue flaps are harvested from the prepuce. Corpus spongiosum has also been used to provide cover to the neourethra. Smith flap is a penile skin based flap, whereas Buck's fascial flap is harvested from the penile shaft. ${ }^{[4]}$ Both have been used in the past to provide additional cover to the neourethra with varying degrees of success. Alternatively, a dartos flap from prepuce or a TVF flap from the tunica vaginalis of the testis can be harvested to cover the neourethra. ${ }^{[3]}$ Several centres 
now recognise the use of TIP urethroplasty introduced by Snodgrass as their primary urethroplasty technique. ${ }^{[5]}$ However, urethral fistula formation is still a bothersome complication following this technique. ${ }^{[6]}$ To prevent this complication, different authors have used various tissues such as buccal mucosa, dartos flap, corpus spongial tissue flap, etc., as an additional cover to the neourethra. ${ }^{[7]}$

The vascularised subcutaneous tissue from dorsal preputial and penile shaft skin was used by Snodgrass as an additional cover for the neourethra. This dissection may compromise the vascularity of the skin cover resulting in necrosis of the skin. ${ }^{[8]}$ Duckett et al. have also described hypovascularity as a cause of skin necrosis following dorsal flap. ${ }^{[6]}$ The dorsal flap has been used to cover the neourethra, but this sometimes results in penile torsion or chordee. In a study by Furness and Hutcheson 2 patients of 109 developed fistula after the use of dartos fascia from the ventral side of penis. ${ }^{[9]}$

TVF described as an alternative in covering the neourethra has many advantages in the form of good vascularity, easy availability and not being affected by penile disorders. ${ }^{[10]}$ Routh et al. described the use of TVF combined with the use of operative microscope and reported that the UCF rate was $0 \%$ with only a $2.2 \%$ complication rate such as scrotal haematoma and abscess. ${ }^{[11]}$

Chatterjee et al., while describing a comparison of dartos (20 cases) and TVF (29 cases) in primary repair of hypospadias, reported zero fistula rate with TVF as opposed to $15 \%$ in dartos group..$^{[12]}$ In our study, the fistula formation resulted in $2 \%$ which was higher as compared to Snow et al. and Chatterjee et al. The explanation for no fistula formation in series by Snow et al. ${ }^{[13]}$ could be the use of the microscope intraoperatively, thus, emphasising the importance of delicate and meticulous tissue handling during hypospadias surgery. In a review of the literature on TIP urethroplasty for distal hypospadias, Braga et al. concluded that the complication rate with TIP urethroplasty techniques is below $10 \% .{ }^{[14]}$ Snodgrass (the pioneer of this operative technique), observed a zero fistula rate in 14 consecutive cases of proximal hypospadias treated with a double-layered urethroplasty and tunica vaginalis cover. ${ }^{[15]}$ As demonstrated by other authors, the fistula formation and other complications are very low with the application of TVF. ${ }^{[16,17]}$

In our series, 16 patients were circumcised and all of them had a successful surgical outcome without fistula formation. The TVF seems to be of particular benefit in circumcised patients because use of dartos flap in them is likely to result in thinning and shortage of skin resulting in damage to intrinsic blood supply and subsequent skin necrosis. Probability of flap necrosis following TVF repair is remote because tissue cover provided on the ventral aspect of the neourethral tube is well-vascularised. In our series, 5 patients operated elsewhere underwent re-do urethroplasty in our centre and none of these 5 patients developed a fistula. As tunica vaginalis is well away from the penile shaft, its blood supply remains undisturbed even after previous surgery of the penis. The low complication rate observed in our series is also reported by other authors..$^{[1,4]}$

The advantages of TVF are multiple. A very low UCF rate, uniformly good blood supply, easy operative access to tunica vaginalis, especially in the hands of an experienced hypospadias surgeon who is well-versed with the surgical anatomy of the scrotum, testis and cord structures makes this technique very useful and versatile for repair of hypospadias. One theoretical concern has been the risk of damage to vas and testicular vessels. Injury to the testicular artery and vas is a remote possibility because the dissection is much distally directed over the tunica vaginalis surrounding the testis.

We encountered one case of post-operative chordee which was probably due to short length of the pedicle resulting in subsequent downward traction of the glans towards the side where from TVF had been harvested. This complication can be avoided by ensuring that the flap is of adequate length and no cremasteric fibres are included in the flap. We believe that the meticulous dissection, gentle tissue handling, ensuring a good length pedicled flap which reaches the recipient site can avoid this complication. Furthermore, it is emphasised that fascia used as second layer is either not available or of poor quality, especially in circumcised and re-do cases; thus, TVF is an excellent option in these circumstances as well. TVF harvested meticulously without tension and proper homeostasis can avoid complications such as scrotal haematoma and haematoma under the flap.

The main limitation of our series was that it was not a comparative study; besides, the number of patients was not quite large. The strength of our study is that it is prospective and procedures were performed by a single surgeon, cases belonging to similar population and follow-up was adequate. 


\section{CONCLUSION}

To conclude, TVF repair has potentially negligible failure rates particularly, UCF formation, and good cosmetic appearance. Although harvesting a TVF flap is time-consuming and relatively difficult procedure, these problems can be conquered as the surgeon crosses the learning curve. Furthermore, careful attention to haemostasis during scrotal dissection can reduce the scrotal complications such as haematoma and abscess formation.

\section{Financial support and sponsorship}

Nil.

\section{Conflicts of interest}

There are no conflicts of interest.

\section{REFERENCES}

1. Snodgrass W. Tubularised, incised plate urethroplasty for distal hypospadias. J Urol 1994;151:464-5.

2. Yang SS, Chen SC, Hsieh CH, Chen YT. Reoperative Snodgrass procedure. J Urol 2001;166:2342-5.

3. Snow BW. Use of tunica vaginalis to prevent fistulas in hypospadias surgery. J Urol 1986;136:861-3.

4. Dhua AK, Aggarwal SK, Sinha S, Ratan SK. Soft tissue covers in hypospadias surgery: Is tunica vaginalis better than dartos flap? J Indian Assoc Pediatr Surg 2012;17:16-9.

5. Steckler RE, Zaontz MR. Stent-free Thiersch-Duplay hypospadias repair with the Snodgrass modification. J Urol 1997;158(3 Pt 2):1178-80.
6. Duckett JW Jr, Kaplan GW, Woodard JR, Devine CJ Jr. Panel: Complications of hypospadias repair. Urol Clin North Am 1980;7:443-54.

7. Ahmed S, Gough DC. Buccal mucosal graft for secondary hypospadias repair and urethral replacement. $\mathrm{Br} J$ Urol 1997;80:328-30.

8. Smith D. A de-epithelialised overlap flap technique in the repair of hypospadias. Br J Plast Surg 1973;26:106-14.

9. Furness PD $3^{\text {rd }}$, Hutcheson J. Successful hypospadias repair with ventral based vascular dartos pedicle for urethral coverage. J Urol 2003;169:1825-7.

10. Tavakkoli Tabassi K, Mohammadi S. Tunica vaginalis flap as a second layer for tubularised incised plate urethroplasty. Urol J 2010;7:254-7.

11. Routh JC, Wolpert JJ, Reinberg Y. Tunneled tunica vaginalis flap is an effective technique for recurrent urethrocutaneous fistulas following tubularised incised plate urethroplasty. J Urol 2006;176(4 Pt 1):1578-80.

12. Chatterjee US, Mandal MK, Basu S, Das R, Majhi T. Comparative study of dartos fascia and tunica vaginalis pedicle wrap for the tubularised incised plate in primary hypospadias repair. BJU Int 2004;94:1102-4.

13. Snow BW, Cartwright PC, Unger K. Tunica vaginalis blanket wrap to prevent urethrocutaneous fistula: An 8-year experience. J Urol 1995;153:472-3.

14. Braga LH, Lorenzo AJ, Salle JL. Tubularised incised plate urethroplasty for distal hypospadias: A literature review. Indian $\mathrm{J}$ Urol 2008;24:219-25.

15. Snodgrass WT. Editorial comment. J Urol 2007;178:1456.

16. Guralnick ML, al-Shammari A, Williot PE, Leonard MP. Outcome of hypospadias repair using the tubularised, incised plate urethroplasty. Can J Urol 2000;7:986-91.

17. Landau EH, Gofrit ON, Meretyk S, Katz G, Golijanin D, Shenfeld OZ, et al. Outcome analysis of tunica vaginalis flap for the correction of recurrent urethrocutaneous fistula in children J Urol 2003;170(4 Pt 2):1596-9. 